\title{
EFFECT OF PYRIDOXAL PHOSPHATE DEFICIENCY ON AROMATIC L-AMINO ACID DECARBOXYLASE ACTIVITY WITH L-DOPA AND L-5-HYDROXYTRYPTOPHAN AS SUBSTRATES IN RATS
}

\author{
Mohammed Khalilur RAHMAN ${ }^{*}$, Toshiharu NAGATSU ${ }^{*}$, Tae SAKURAI ${ }^{* *}$, \\ Seiji HORI***, Miyako ABE ${ }^{* * *}$ and Makoto MATSUDA** \\ Laboratory of Cell Physiology, Department of Life Chemistry. \\ Graduate School at Nagatsuta, Tokyo institute of Technology, Yokohama 227, Japan
}

Accepted May 10, 1982

\begin{abstract}
This paper describes the distribution of aromatic L-amino acid decarboxylase (AADC) activities in fourteen tissues (eight peripheral tissues and six brain regions) of semicarbazide (SC)-treated rats, using both $L$ DOPA and L-5-hydroxytryptophan (L-5-HTP) as substrates. The distribution of pyridoxal phosphate (PLP) was also measured in control and SC-treated rats. SC-treatment decreased the PLP concentration in all tissues (about 50-60\% of control). AADC activities towards L-DOPA and L-5-HTP as substrates were also decreased significantly in almost all tissues of SC-treated rats. After the addition of exogenous PLP in vitro. AADC activities were recovered only partially in most tissues, but the recovery patterns were not parallel between L-DOPA and L-5-HTP as substrates. $L$-DOPA decarboxylase activity was more sensitive to PLP-deficiency than L-5-HTP decarboxylase activity in the same tissues. Serum AADC activities were decreased drastically using both L-DOPA and L-5-HTP as substrates. No serum AADC activity was detected in SC-treated rats using L-DOPA as substrate, but low activity was detected in the same sample using L-5-HTP as the substrate; both activities recovered completely after in vitro addition of $10 \mu \mathrm{M}$ PLP in the incubation mixtures.
\end{abstract}

Aromatic L-amino acid decarboxylase (AADC, EC. 4.1.1.28) (1) catalyzes the decarboxylation of L-DOPA and $L-5-$ hydroxytryptophan (L-5-HTP) to dopamine (DA) and 5-hydroxytryptamine (5-HT). respectively, in peripheral tissues and the brain. This enzyme requires pyridoxal phos-

*Visiting Fellow supported by Japanese Government (Ministry of Education. Science and Culture) from the Department of Biochemistry. University of Rajshahi, Rajshahi. Bangladesh.

*To wham correspondence ard reprint reouests should be sent.

***Department of Biachemistry, The Jikei University School of Medicine, Tokyo 105, Japan. phate (PLP) as the prosthetic group for its activity (2). Some PLP is tightiy bound to the apoenzyme as a Schiff's base, whereas another portion is dialyzable (3). The purified AADC of hog kidney contains 0.7-1.1 mole of PLP per $112,000 \mathrm{~g}$ of protein. The activity of the enzyme preparations is increased 2 - to 5 -fold on addition of PLP at $5 \times 10^{-6}-1 \times 10^{-4}$ $M$ (4). It had been suggested that L-DOPA decarboxylase and L-5-HTP decarboxylase are distinct enzymes, and the Enzyme Commission had assigned separate numbers for them. Later evidence, however, confirmed that a single enzyme acts on both substrates 
(4.5). Still the presence of more than one decarboxylase for aromatic amino acids in animal tissues has been suggested $(3,6)$.

Ebadi (7) has discussed the regulation and function of PLP in the central nervous system in his recent review article. However, up to now, no complete study of the effect of PLP deficiency on AADC activities using both $L$ DOPA and L-5-HTP as substrates in central and peripheral tissues and serum of mammals has been available. It has been found that a decrease of PLP in the brain also decreases the $\alpha$-ketoglutarate aminotransferase level (8, 9). On the other hand, some studies have been made on mouse brain concerning its content of PLP (10), subcellular distribution of $B_{6}$-vitamers (11), and effect of pyridoxal $(P L)$ administration on the control of PLP and $\gamma$-aminobutyric acid (12). However, no thorough study of PLP distribution in control and vitamin $B_{6}$-deficient brain regions and peripheral tissues and serum has yet been made to elucidate its relationship to AADC.

With the aim of making a detailed biochemical study of AADC in mammals using both L-DOPA and L-5-HTP as substrates, we have already established new and highly sensitive assay methods for L-DOPA decarboxylase (13) and L-5-HTP decarboxylase (14), and we have made systematic studies of AADC: its distribution in peripheral tissues and brain regions (15) and in animal sera (16), developmental changes in rat serum (17), distribution and properties in human brain regions, and changes in diseases $(18,19)$

In this paper, we describe a systematic study of the effect of PLP deficiency on the tissue distribution of AADC with L-DOPA and L-5-HTP as substrates in fourteen different peripheral and brain tissues. It had been shown that the in vivo administration of semicarbazide (SC) reduced the concentration of PLP in the brain which resulted in convulsion-fits and that when the convulsions were prevented by simultaneous administration of pyridoxine. $\mathrm{PL}$, or pyridoxamine, the PLP level rose to the normal level (10). For our present study, therefore, the rats were treated with SC to produce PLP-deficiency.

\section{MATERIALS AND METHODS}

Materials: L-DOPA, L-5-HTP, D-DOPA, $\mathrm{N}$-methyldopamine (N-M-DA), and pargyline. $\mathrm{HCl}$ were obtained from the Sigma Chemical Co., St. Louis Mo; SC and PLP from Nakarai Chemicals. Kyoto; Amberlite CG-50 and CG-120 from Rohm and Hass. Philadelphia, PA: EDTA from Tokyo Kasei. Tokyo: and ascorbic acid from Wako Pure Chemicals, Tokyo. 3,4-Dihydroxybenzylamine (DHBA) and carbidopa were generous gifts from the Eizai Pharmaceutical Co., Tokyo and the Sankyo Pharmaceutical Co., Tokyo. respectively. All other chemicals were of analytical grade.

Administration of drugs and preparation of tissues: Twenty Donryu male rats (weighing about $300 \mathrm{~g}$ ) were divided into 2 groups (10 rats in each group). Each rat of the experimental group received a dose of $90 \mathrm{mg}$ of SC $(300 \mathrm{mg} / \mathrm{kg}$ body weight) intraperitoneally. The solution of SC was prepared freshly in saline solution, and the dose was administered $80 \mathrm{~min}$ before decapitation. Each rat of the control group received a similar volume of saline alone $80 \mathrm{~min}$ before decapitation. Immediately after decapitation. the liver, kidney, adrenals, heart, lung. spleen, pineal gland, brain stem, colliculi, caudate nucleus, hypothalamus, cerebral cortex, and cerebellum were dissected and stored at $-80^{\circ} \mathrm{C}$ until use. Serum was also collected. For the purpose of the AADC assay, the peripheral tissues were homogenized (5-10 fold dilution) with $0.25 \mathrm{M}$ sucrose in a Potter glass homogenizer. The brain tissues were homogenized in the same way, but with $0.32 \mathrm{M}$ sucrose. The pineal 
gland and hypothalamus were diluted 200 and 20 times, respectively. Rat serum was not diluted. The volume of homogenate used for the assay contained the weight of tissue shown in Table 2.

Extraction, separation, and determination of PLP: For the extraction, separation, and determination of tissue PLP. we followed our modified methods of extraction, separation, and determination of $B_{6}$-vitamer (20). In this study, we measured the PLP alone according to the following procedures: The tissues (20-50 mg) were blotted on moist filter paper to remove traces of blood and weighed. For the pineal gland preparation. five pineal glands were pooled together and weighed $(7.0 \mathrm{mg})$. One $\mathrm{ml}$ of serum was used for the extraction. The tissue was homogenized with 9 volumes of cold $1 \mathrm{M}$ perchloric acid and then centrifuged at 15,000 r.p.m. for $20 \mathrm{~min}$, and the supernatant was neutralized with $5 \mathrm{M} \mathrm{KOH}(\mathrm{pH} \mathrm{3-4).} \mathrm{PLP}$ contained in the supernatant was separated from other $B_{6}$-vitamers by chromatography with Amberlite CG-120 (200-400 mesh). The resin in the $\mathrm{Na}^{+}$cycle was equilibrated to $\mathrm{pH} 3.5$ with $0.01 \mathrm{M}$ sodium acetate buffer. slurred in the same buffer, and packed in a column $(4 \times 17.5 \mathrm{~mm})$ with a reservoir of $10 \mathrm{ml}$ capacity. The extract $(1.2 \mathrm{ml})$ was percolated through $0.2 \mathrm{ml}$ of resin and was washed through the column with $0.5 \mathrm{ml}$ of water. The first $1.7 \mathrm{ml}$ of effluent was collected in one fraction and held for the assay of PLP. The flow rate through the column was about $0.02 \mathrm{ml} / \mathrm{min}$. By this method, pyridoxine phosphate, PLP, and PLP-SC complex were eluted in the same fraction: the two phosphate esters were hydrolyzed by the action of acid phosphatase $(0.5 \mathrm{mg} / \mathrm{ml}$, incubation for $60 \mathrm{~min}$ at $37^{\circ} \mathrm{C}$ ) and the reaction was stopped by heating at $100^{\circ} \mathrm{C}$ for $5 \mathrm{~min}$. The PL formed from PLP was separated by re-chromatography using the same type of Amberlite CG-120 column. The supernatant was passed through the column and was washed successively with $0.5 \mathrm{ml}$ of water and $1 \mathrm{ml}$ of $0.1 \mathrm{M}$ acetate buffer, $\mathrm{pH} \mathrm{5.0}$; the PL fraction was eluted with $1 \mathrm{ml}$ of $0.1 \mathrm{M}$ phosphate buffer, pH 6.0.

PL obtained from PLP by the action of acid phosphatase was assayed microbiologically with Saccharomyces carlbergensis (ATCC 9080) against its reference standard which was dissolved in saturated K-perchlorate and treated on the column in the same way. The assay method was modified from that of Chiao and Peterson (21). Aliquits were added to $2.5 \mathrm{ml}$ of base media, and the volume was made to $5.0 \mathrm{ml}$ with water. Following $20 \mathrm{~min}$ sterilization, the tubes were inoculated with $0.05 \mathrm{ml}$ of diluted 20 -hr yeast culture grown (optical density at $610 \mathrm{~nm}=0.3$ ) on limited $\mathrm{B}_{6}$ media. The tubes were incubated for $20 \mathrm{hr}$ at $30^{\circ} \mathrm{C}$ in an incubator. Growth was estimated by reading at $610 \mathrm{~nm}$ in a colorimeter.

\section{Assay methods for DOPA decarboxylase} and 5-HTP decarboxylase activities: Both DOPA decarboxylase and L-5.HTP decarboxylase activities in various tissues, except serum, were measured mainly by fluorometry based on the native fluorescence of DA and 5-HT as described in our previous studies (15). The incubation mixtures and assay procedures for DOPA decarboxylase and 5 HTP decarboxylase were exactly the same as described in our previous paper (16). However, (a) in the studies of the effect of exogenous PLP addition in vitro, no PLP was added in the incubation mixtures, and (b) instead of D-5-HTP, in this study, we used L-5-HTP plus $100 \mu \mathrm{M}$ of carbidopa, an AADC inhibitor, for the blank.

Serum DOPA decarboxylase and 5-HTP decarboxylase activities were measured by our highly sensitive assay methods using high-performance liquid chromatography (HPLC) with electrochemical detection (14. 15). The assay procedures for serum L-DOPA decarboxylase were as follows: One hundred 
$\mu l$ of serum were used as the enzyme source in the incubation mixtures (15), and the incubation was done for $20 \mathrm{~min}$. Ten minutes after the addition of $3 \mathrm{M}$ trichloroacetic acid, $1.87 \mathrm{ml}$ of water and 50 " of of $0.01 \mathrm{M} \mathrm{HCl}$ containing 31-62.5 pmoles of DHBA as an internal standard were added, and the mixture was centrifuged. The supernatant was passed through the Amberlite CG-50 column, and after washing the column. DA was eluted with $700 \mu$ of $1 \mathrm{M} \mathrm{HCl}$. One hundred or two hundred $\not l$ of the eluate were injected into the HPLC (Yanaco L-2000) with a Yanaco VMD-101 electrochemical detector and a 'nucleosil' reversed-phase column (particle size of $7 \mu \mathrm{m}, 25.0 \times 0.4 \mathrm{~cm}$ i.d. column for the liquid chromatography). The carrier buffer was $0.1 \mathrm{M}$ potassium phosphate buffer, $\mathrm{pH} 3.2$, containing $0.5 \%$ acetonitrile. with a flow rate of $0.8 \mathrm{ml} / \mathrm{min}$. The peak height of DA was measured and converted to pmoles based upon DHBA added as an internal standard. The retention time under these conditions was: DHBA, 5.5 min:
DOPA, $7.0 \mathrm{~min}$; and DA, $8.5 \mathrm{~min}$.

Serum 5-HTP decarboxylase activity was measured as described in our previous studies $(14,15)$. One hundred $\mu$ l of serum were used in the incubation mixtures as the enzyme source and the incubation was done for $240 \mathrm{~min}$. with 500 pmoles of N-M-DA added as an internal standard. Procedures for HPLC were the same as described for serum L-DOPA decarboxylase except that the adsorbed 5-HT was eluted with $1.4 \mathrm{ml}$ of $1 \mathrm{M}$ $\mathrm{HCl}$, and the carrier buffer for liquid chromatography was $0.2 \mathrm{M}$ citrate buffer, $\mathrm{pH} 2.2$. with a flow rate of $1.1 \mathrm{ml} / \mathrm{min}$. The retention times under these conditions were: $N-M-D A$. $6.0 \mathrm{~min}$; 5-HT, $11.5 \mathrm{~min}$; and 5-HTP. $13.5 \mathrm{~min}$

\section{RESULTS}

Tissue distributions of PLP concentration in fourteen tissues and brain regions of control and SC-treated rats are shown in Table 1. Control rats had the highest PLP concentration in the liver, followed by the

Table 1. Tissue distribution of PLP concentration in control and SC-treated rats.

\begin{tabular}{|c|c|c|}
\hline \multirow{2}{*}{ Tissue } & \multicolumn{2}{|c|}{$\begin{array}{c}\text { PLP concentration (nmoles/g tissue) } \\
\text { mean } \pm S . E . M\end{array}$} \\
\hline & Control & SC-treated \\
\hline Pineal gland & $8.1^{\#}$ & $4.4^{*}$ \\
\hline Liver & $25.2 \pm 2.3$ & $10.3 \pm 1.1^{* * *}$ \\
\hline Kidney & $8.4 \pm 0.7$ & $7.0 \pm 1.3$ \\
\hline Adrenal gland & $4.4 \pm 0.5$ & $2.5 \pm 0.2^{* *}$ \\
\hline Caudate nucleus & $6.8 \pm 0.5$ & $2.4 \pm 0.4^{* * *}$ \\
\hline Hypothalamus & $7.9 \pm 0.1$ & $3.3 \pm 0.5^{*}$ \\
\hline Colliculi & $7.0 \pm 1.3$ & $3.2 \pm 0.5^{* *}$ \\
\hline Brain stem & $6.9 \pm 0.6$ & $3.7 \pm 0.5^{* *}$ \\
\hline Cerobral cortex & $6.2 \pm 0.5$ & $2.0 \pm 0.2^{* * *}$ \\
\hline Cerebellum & $6.9 \pm 0.5$ & $3.8 \pm 0.5^{* * *}$ \\
\hline Lung & $3.6 \pm 0.1$ & $1.1 \pm 0.05^{* * *}$ \\
\hline Heart & $6.4 \pm 0.4$ & $3.2 \pm 0.4^{* * *}$ \\
\hline Spleen & $3.2 \pm 0.4$ & $1.9 \pm 0.2^{* * *}$ \\
\hline Blood serum & $0.8 \pm 0.058$ & $0.1 \pm 0.01 * * * 8$ \\
\hline
\end{tabular}

\# Five pineal glands were pooled together for measurement.

$\$ n$ moles $/ \mathrm{ml}$ serum.

** $P<0.001: * * P<0.01: * P<0.05$ as compared with the control. 
kidney, pineal gland, hypothalamus, colliculi, brain stem, caudate nucleus, cerebellum. cerebra! cortex, and heart. The PLP concentration was comparatively low in the adrenal glands, lung, and spleen. In serum, the concentration of PLP was $0.8 \mathrm{nmol} / \mathrm{ml}$ serum. The PLP concentration was significantly lower in almost all tissues after SC treatment: the serum PLP concentration was decreased drastically from $0.8 \mathrm{nmole} / \mathrm{ml}$ serum to 0.1 nmole $/ \mathrm{ml}$ serum $(\mathrm{P}<0.001)$ by this means; and similar effects were observed in the liver. caudate nucleus, lung, cerebral cortex, heart, cerebellum and spleen $(P<0.001$ in all these tissues). Only the kidney PLP concentration did not decrease significantly after SC

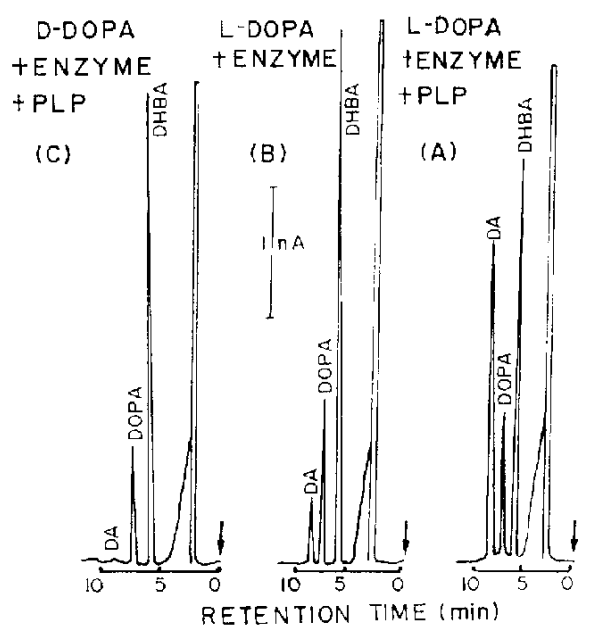

Fig. 1. Elution pattern of L-DOPA decarboxylase incubation mixtures in HPLC showing the effect of PLP in the incubation mixtures with the serum of a control rat as the enzyme source. Incubations were done at $37^{\circ} \mathrm{C}$ for 20 min using $100 \mu$ of serum. Key: (A) Experimental in. cubation with L-DOPA and 10 "MM PLP. (B) experimental incubation witholit PLP. and $(C)$ blank incubation with D-DOPA and $70 \% \mathrm{M}$ PLP. After incubation, 62.5 pmoles of 3.4 dihydroxybenzylamine (DHBA) were added to each sample as an internal standard. L-DOPA. decarboxylase activity was calculated to be 36.1 pmoles $/ \mathrm{min} / \mathrm{ml}$ serum and 5.4 pmoles $/ \mathrm{min} / \mathrm{ml}$ serum from chromatograms (A) and (B). respectively. treatment.

Chromatograms in Fig. 1 show the HPLC elution pattern of L-DOPA containing incubation mixtures with control rat serum. Figure $1(A)$ shows the elution pattern after addition of $10 \mu \mathrm{M}$ PLP to the incubation mixtures, and Fig. 1(B) shows the activity of the enzyme without such an addition. Figure 1(C) shows the result with D-DOPA as the substrate.

Chromatograms in Fig. 2 show the corresponding HPLC elution pattern for SCtreated rat serum. There is no enzyme activity without addition of exogenous PLP to the incubation mixtures (Fig. 2B); but after the addition of $10 \% \mathrm{M}$ PLP, the activity is recovered completely (Fig. 2A). Figure 2(C) shows the chromatograms with D-DOPA as

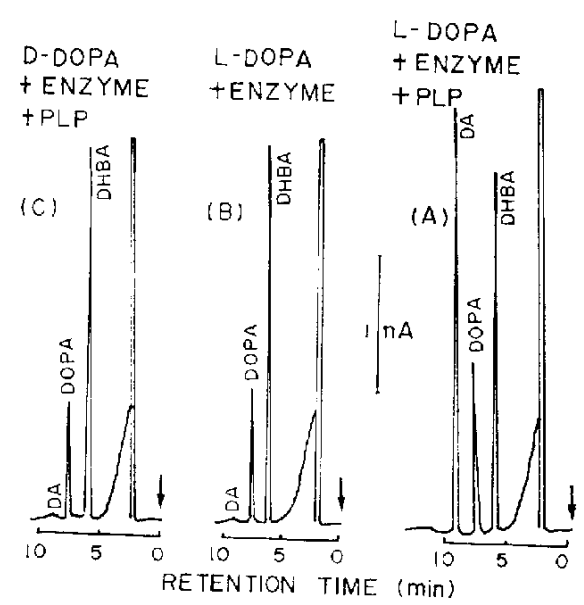

Fig. 2. Elution pattorn of L-DOPA decarboxylase incubation mixtures in HPLC showing the effect of PLP in the incubation mixtures with SC-treated rat scrum as an enzyme source. Incubations were done at $37^{\circ} \mathrm{C}$ for 20 min using $100 \mu$ of serum. Key: (A) Experimental incubation with L-DOPA and $10 \mu M$ PLP, (B) experimental incubation without PLP, and (C) blank incubation with D-DOPA and $10, a \mathrm{M}$ PLP. After incubation, 31 pmoles of 3,4dihycroxybenzylamine (DHBA) were added to each sample as an internal standard. L-DOPA decarboxylase activity was $28.0 \mathrm{pmoles} / \mathrm{min} / \mathrm{ml}$ serum as calculated from the chromatograms of (A). 


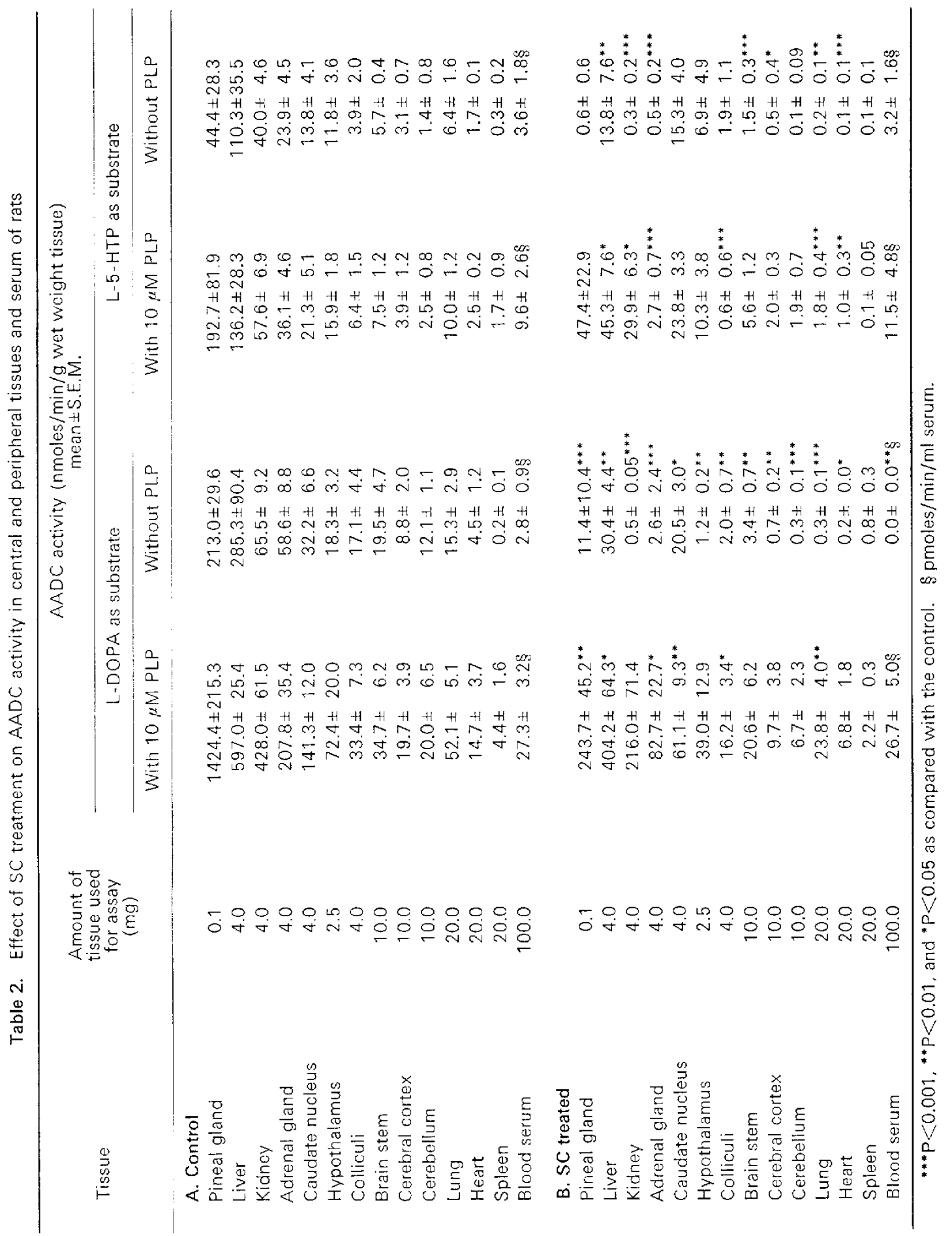


the substrate.

To demonstrate the effect of SC treatment in causing PLP deficiency in vivo, the incubation was done without the addition of PLP to the incubation mixtures; it was observed that L-DOPA decarboxylase activity was decreased significantly in almost all tissues of the SC-injected rats as shown in Table 2. L-DOPA decarboxylase activity was decreased greatly by SC in the pineal gland, kidney, adrenal glands, cerebellum, and lung ( $P<0.001$ in all these tissues): the serum, liver, hypothalamus, colliculi, brain stem, and cerebral cortex $(P<0.01$ in all these tissues): and the caudate nucleus and heart $(P<0.05)$. Addition of $10 \mu \mathrm{M}$ of $\mathrm{PLP}$ to the incubation mixtures permitted L-DOPA decarboxylase activity to recover completely in the serum and to a lesser, but significant, extent in some tissues, e.g., the kidney. hypothalamus, cerebral cortex, cerebellum. heart, and spleen. However, L-DOPA decarboxylase activity was still significantly low in the pineal gland, caudate nucleus, liver, adrenal gland, and colliculi. even after the addition of PLP in the incubation mixtures with tissues homogenates from SC-treated rats as compared with that of control rats.

L-5-HTP decarboxylase activity was also decreased greatly in the kidney, adrenal glands, brain stem, and heart $(P<0.001)$ : the liver and lung $(P<0.01)$; and the cerebral cortex $(P<0.05)$ of $S C$-treated rats. After addition of PLP to the incubation mixtures, L-5-HTP decarboxylase activity recovered significantly in the serum, caudate nucleus. brain stem, cerebral cortex, and cerebellum of SC-treated rats; but in the adrenal glands, colliculi, lung, heart, liver, and kidney, the activity was only partially restored and was still low in comparison with that of control rats, even after addition of exogenous PLP in the incubation mixtures.

\section{DISCUSSION}

AADC requires PLP as a coenzyme for its activity (2), but up to now, no study has been made to observe the effect of PLP deficiency on this enzyme in vivo using both L-DOPA and L-5-HTP as substrates. Immunochemical and biochemical data on homogeneous AADC purified from the hog kidney support the view that a single enzyme can decarboxylate both L-DOPA and L-5-HTP $(4,5)$. Several reports have been published, however. that indirectly support the presence of two types of AADC with relatively high activity either for L-DOPA or for L-5-HTP $(3,6)$.

As an approach to observe the effect of $\mathrm{B}_{6}$-deficiency on AADC in mammals, we measured the activities of L-DOPA decarboxylase and L-5-HTP decarboxylase in the peripheral tissues, brain regions, and serum of SC-treated rats, with or without PLP in the incubation mixtures; and the results were compared with those of control rat tissues obtained by the same procedures. We also first measured the detailed distribution of PLP in the peripheral tissues, brain regions, and serum of control and SC-treated rats.

There have been several reports concerning the decrease of $B_{6}$ concentration in mammals after treatment with anti- $B_{6}$ drugs (8-10,12). After administration of an anti- $B_{6}$ (for example, SC). PLP levels in the brain decreased, the activity of glutamate decarboxylase (GAD) was inhibited, and the level of $\gamma$-aminobutyric acid (GABA) in the brain was decreased $(12,22)$.

In our present studies, it was found that the PLP concentration was highest in the liver, followed by the kidney, pineal gland, hypothalamus, colliculi, and brain stem. AADC activities were also high in the abovementioned tissues for both L-DOPA and L-5-HTP, but the ratio of the activities for L-DOPA and L-5-HTP was not constant. Serum had the lowest PLP concentration, 
and the activity of AADC was also lowest in the serum. In this study, we obtained somewhat low serum AADC activities using both the substrates as compared with our previous results $(15,16)$. This may be due to species differences and the physiological conditions of the rats.

PLP concentration was decreased significantly in all tissues except the kidney after treatment of rats with SC intraperitoneally. L-DOPA decarboxylase activity was found to be decreased significantly in all tissues except spleen when measured without exogenous PLP in the incubation mixtures. After SC-treatment, L-5-HTP decarboxylase activity was also decreased significantly in some tissues but not in all tissues when measured without exogenous PLP in the incubation mixtures. No L-DOPA decarboxylase activity was detected in SCtreated rat sera, but low activity was detected for L-5-HTP decarboxylase in the same sera. Thus, L-DOPA decarboxylase activity was more sensitive to PLP deficiency than L-5HTP decarboxylase activity in the same tissues. Although PLP in the kidney did not decrease significantly in the SC-treated rats, AADC activities with both L-DOPA and L-5-HTP as substrates were decreased markedly. The reason for this is not clear.

After addition of $10 \mu \mathrm{M}$ PLP in vitro in the incubation mixtures, the activities restored completely in the serum and to a great extent in some tissues, but were still low in other tissues. The reason why the activities did not restore completely in some tissues, even after addition of PLP in the incubation mixtures, may be that the enzyme became unstable by SC-treatment, resulting in irreversible conformational changes in the enzyme molecule. Also the recovery of the activity was not parallel between L-DOPA decarboxylase and L-5-HTP decarboxylase.

The present results on the simultaneous reduction of PLP and AADC activities with
L-DOPA and L-5-HTP as substrates in SCtreated rats and the recovery of $A A D C$ activities by the in vitro addition of PLP support the view that PLP is the cofactor of $A A D C$ in vivo. The results that both the degree of decrease in AADC activities by PLP deficiency and the degree of the recovery by in vitro addition of PLP with DOPA and 5-HTP as substrates were not parallel suggest the possibility of the presence of two different AADC with different affinities for DOPA and 5-HTP. This hypothesis should be verified by isolating the enzyme from different tissues.

Acknowledgement: This work was supported by grants from the Ministry of Health and Welfare and from the Ministry of Education, Science and Culture to T.N.

\section{REFERENCES}

1) Lovenberg. W., Weissbach, $H$. and Udenfriend, S.: Aromatic L-amino acid decarboxylase. J. biol. Chem. 237, 89-93 (1962)

2) Holtz, P. and Bachman, F.: Activierung der Dopadecarboxylase des Nebennierenmarks durch Nebennieren-Rindenextrakt. Naturwissenschaften 39, 116-117 (1952)

3) Awapara, J., Sandman, R.P. and Hanley, C.: Activation of dopa decarboxylase by pyridoxal phosphate. Arch. Biochem. Biophys. 98, 520525 (1962)

4) Christenson, J.G., Dairman, W. and Udenfriend, S.: Preparation and properties of a homogenous aromatic L-amino acid decarboxylase from pig kidney. Arch. Biochem. Biophys. 141, 356-367 (1970)

5) Christenson, J.G., Dairman, W. and Udenfriend, S.: On the identity of DOPA decarboxylase and 5-hydroxytryptophan decarboxylase. Proc. natn. Acad. Sci. U.S.A. 69, 343-347 (1972)

6) Sims, K.L., Davis, G.A. and Bloom, F.E.: Activities of 3,4-dihydroxyphenylalanine and 5 -hydroxytryptophan in rat brain: Assay characteristics and distribution. J. Neurochem. 20, 449-464 (1973)

7) Ebadi, M: Regulation and function of pyridoxal phosphate in CNS. Neurochem. Intl. 3, 181206 (1981)

8) Tapia, R., Pérez, De La Mora, M. and Massieu, G.M.: Correlative changes of pyridoxal kinase, pyridoxal-5-phosphate and glutamate decarboxylase in brain, during drug-induced 
convulsions. Ann. N.Y. Acad. Sci. 166, 257266 (1969)

9) Minard, F.N.: Relationships among pyridoxal phosphate, vitamin $B_{6}$-deficiency, and convulsions induced by 11 -dimetinylhydrazine. J. Neurochem. 14, 681-692 (1967)

10) Sakurai, T., Kuwahara, T. and Matsuda, M.: Vitamin $B_{G}$ vitamers in mouse brain and their relationship to convulsions. Jikeikai Med. J. 27, 13-21 (1980)

11) Sakurai, T., Kuwahara, T. and Matsuda, $M_{\text {: }}$ Subcellular distribution of $B_{6}$ vitamers in mouse brain. Jikeikai Med. J. 27, 151-158 (1980)

12) Eto, K., Takahashi, Y., Hoshino, M., Sakurai, T. and Matsuda, M.: Effect of pyridoxal administration on the contents of pyridoxal phosphate and $\gamma$-aminobutyric acid in mouse brain. $J$. Nutr. Sci. Vitaminol. 24, 255-262 (1978)

13) Nagatsu, T., Yamamoto, $T$. and Kato, T.: A new and highly sensitive voltammetric assay for aromatic L-amino acid decarboxylase activity by high-porformance liquid chromatography. Analyt. Biochem. 100, 160-165 (1979)

14) Rahman, M.K., Nagatsu, T. and Kato, T.: New and highly sensitive assay for L-5-hydroxytryptophan decarboxylase activity by highperformance liquid chromatography-voltammetry. J. Chromatogr. 221, 265-270 (1980)

15) Rahman, M.K., Nagatsu, T, and Kato, T.: Aromatic L-amino acid decarboxylase activity in central and peripheral tissues and serum of rats with L-DOPA and L-5-hydroxytryptophan as substrates. Biochem. Pharmacol. 30, 645649 (1981)

16) Rahman, M.K., Nagatsu, T. and Kato, T.:
Determination of aromatic L-amino acid decarboxylase in serum of various animals by high-performance liquid chromatography with electrochemical detection. Life Sci. 28, 485492 (1981)

17) Rahman, M.K. and Nagatsu, T.: Developmental changes in rat serum aromatic $L$-amino acid decarboxylase with L-DOPA and L-5-hydroxytryptophan as substrates. Biochem. Intl. 3, 603609 (1981)

18) Rahman, M.K. and Nagatsu, T.: Demonstration of aromatic $L$-amino acid decarboxylase activity in human brain with L-DOPA and L-5-hydroxytryptophan as substrates by high-performance liquid chromatography with electrochemical detection. Neurochem. Intl. 4, 1-6 (1982)

19) Rahman, M.K., Nagatsu, T., Nagatsu, I., lizuka, R. and Narabayashi, H.: Aromatic L-amino acid decarboxylase activity in brains from normal human subjects and from patients with extrapyramidal diseases. Biomed. Res. 2, 560-566 (1981)

20) Murakami, $Y$. and Matsuda, M.: The effect of castrix (2-chloro-4-dimethylamino-6-methylpyrimidine) on the distribution of $B_{6}$ vitamers in mouse brain. Biochem. Pharmacol. 25, 639$642(1976)$

21) Chiao, J.S. and Peterson, W.H.: Some factors affecting the action of thiamine on the growth of Saccharomyces carlsbergensis. Arch. Biochem. Biophys. 64, 115-128 (1956)

22) Abe, M. and Matsuda, M.: $\gamma$-Aminobutyric acid metabolism in subcellular particles of mouse brain and its relationship to convulsions. J. Biochem. 82, 195-200 (1977) 